Universidade Tecnológica Federal do Paraná - UTFPR

Campus Ponta Grossa - Paraná - Brasil

ISSN: 1981-3686/ v. 07, n. 02: p. 1022-1032, 2013

D.O.I.: $10.3895 / \mathrm{S} 1981-36862013000200002$
Revista Brasileira de Tecnologia

Agroindustrial

\title{
CARACTERÍSTICAS FÍSICAS E FÍSICO-QUÍMICAS DA ÁGUA DE FRUTOS DE COQUEIRO ANÃO VERDE
}

\section{PHYSICAL AND PHYSICAL-CHEMICAL CHARACTERISTICS OF COCONUT WATER FROM GREEN-DWARFED COCONUT PALM}

Leirson Rodrigues da Silva ${ }^{1}$; Norma Danielle Silva Barreto ${ }^{2}$; Vander Mendonça ${ }^{3}$; Thayane Rabelo Braga ${ }^{4}$

${ }^{1,2,3}$ Universidade Federal Rural do Semiárido - UFERSA, Mossoró-Brasil leirsonrodrigues@ yahoo.com.br

${ }^{4}$ Universidade Federal do Ceará-UFC, Fortaleza-Brasil

\section{Resumo}

Nos últimos anos, agricultores da região Nordeste vêm cultivando o coqueiro, visando à comercialização da água do fruto verde. Na literatura ainda são poucos os relatos sobre a produção e qualidade do coco verde na região. Tendo em vista obter informações sobre a qualidade do coco e da água do fruto in natura, foi elaborado o trabalho. Os frutos foram colhidos do Estado do Rio Grande do Norte. Após a colheita, foram conduzidos para o laboratório de PósColheita da UFERSA, em Mossoró, RN. Foram realizadas avaliações físicas nos frutos: diâmetro transversal $(\mathrm{cm})$, diâmetro longitudinal $(\mathrm{cm}), D L / D T$, massa fresca $(\mathrm{Kg})$, volume de água $(\mathrm{mL}) e$ MF/VA ( $\left.\mathrm{mL} . \mathrm{kg}^{-1}\right)$ e, avaliações físico-químicas da água de coco: sólidos solúveis ( ${ }^{\circ}$ Brix), $\mathrm{pH}$, acidez titulável (\%) e SS/AT. $O$ experimento foi conduzido em delineamento inteiramente casualizado, em arranjo fatorial $2 x 3$, com quatro repetições. Com relação ao diâmetro transversal e longitudinal, o ambiente de Assu-RN apresentou os maiores valores, com médias de 15,41 e 19,84 $\mathrm{cm}$, respectivamente. Para a relação DL//DT, o ambiente de Natal-RN apresentou valor médio de 1,30. Em relação à massa fresca e volume de água, o ambiente de Assu-RN, obteve maior valor médio (2.151,90 kg e 464,13 mL, respectivamente). Para a relação VA/MF, Natal-RN, apresentou maior valor médio $\left(5,35 \mathrm{~mL} \mathrm{~kg}^{-1}\right)$. Foi possível observar que ocorreram diferenças, para todas as características físico-químicas avaliadas. Entretanto, os valores médios de Natal-RN, foram superiores em todos os atributos avaliados, com acidez de 0,003\%, sólidos solúveis 6,36 ${ }^{\circ}$ Brix, SS/AT 389,48 e pH 4,80.

Palavras-chave: Cocus nucifera L., caracterização, qualidade, volume de água.

\section{Introdução}

O coqueiro é uma planta monocotiledônea, pertencente à família Palmae. É constituído de uma só espécie (Cocus nucifera L.). O fruto do coqueiro é botanicamente, uma drupa, sendo formado por uma epiderme lisa ou epicarpo, que envolve o mesocarpo espesso e fibroso, ficando mais para o interior uma camada muito dura, o endocarpo (PASSOS, 1998). É uma palmeira tipicamente tropical, classificada como uma das oleaginosas mais importantes do mundo. Dentre os 
diversos produtos manufaturados do seu fruto, direta ou indiretamente, os de maior importância comercial são a sua polpa, o óleo, a fibra e, atualmente, a água de coco (BRASIL, 2004).

No Brasil, a área colhida de coco é de, aproximadamente, 283,930 mil hectares e a região Nordeste é responsável por 228,416 mil hectares da produção nacional (IBGE, 2007). Os maiores produtores no Brasil, são os estados do Espírito Santo com (14,378 frutos por hectare) seguido do Rio de Janeiro (13,339 frutos por hectare). Os estados da Região Nordeste são os que apresentam menor produtividade, sendo a Bahia com 5.212 e o Ceará com 5.070 frutos por hectare.

Existem diversas variedades de coqueiros anões, dentre elas podemos citar anã verde, anã vermelho e anã amarelo. Esses coqueiros apresentam frutos com um teor de água e de polpa mais doce que o coco comum e uma produtividade também mais elevada, chegando a 300 frutos por ano, com um volume médio de água no fruto de 300 mL (ARAGÃO et al., 2001).

No Brasil, a disponibilidade de informações quanto às mudanças nas características físicoquímicas da água de coco, durante o desenvolvimento do fruto, são bastante limitadas. Tais informações são fundamentais para a determinação da idade mais adequada para colheita do coco, quando se destina ao fornecimento de água para consumo ao natural ou para o envasamento industrial. Por outro lado, os poucos trabalhos existentes na literatura internacional fazem referência à caracterização da água de coco de variedades gigante ou híbrida, geralmente, referindo-se ao fruto nas fases finais da maturação (SREBERNICH, 1998).

O coco verde ou jovem é consumido em países produtores como uma refrescante bebida, saborosa e nutritiva, que pode ser uma boa fonte de minerais na alimentação, sendo barato e abundante em regiões tropicais (ALEIXO; NÓBREGA, 2000). A água-de-coco verde para ser processada comercialmente deve ter o ${ }^{\circ}$ Brix e $\mathrm{pH}$ próximo de 5,0 e 5,2, respectivamente. É recomendável uniformizar o estádio de maturação e a cultivar, pois os teores de açúcar e ácido influenciam a qualidade sensorial do fruto (EMBRAPA, 1998).

A preocupação com a saúde e a forma física tem-se apoiado também nas bebidas naturais, que visam repor as perdas de água, vitaminas e sais minerais sofridas durante grande esforço físico no trabalho, em esporte e em divertimentos. Dessa forma, existe uma atração dos consumidores por novos produtos e uma tendência por sabores exóticos, naturais, ligados à saúde, a exemplo da águade-coco (CUENCA et al., 2002).

A água-de-coco é uma bebida natural, pouco calórica, com sabor agradável, conhecida mundialmente e muito apreciada em todo o Brasil, principalmente nas regiões litorâneas. Seu consumo vem crescendo nos últimos tempos, principalmente devido às suas propriedades de reposição de eletrólitos perdidos após uma desidratação ou desgaste físico (AROUCHA e VIANNI, 2002). 
De acordo com Oliveira et al. (1999) os aspectos físicos dos frutos referentes à aparência externa, tamanho, forma e cor da casca, constituem atributos de qualidade importantes para comercialização dos frutos. As transformações físico-químicas dos frutos ocorrem durante todo o processo de maturação, afetando constituintes como ácidos, amido, açúcares, ácido ascórbico, umidade, entre outros. Estas variáveis físico-químicas são atributos de qualidade dos frutos comercializados in natura, assim como, os destinados ao processamento. A acidez e os sólidos solúveis são as variáveis que mais interessam à indústria de processamento de frutos (CHITARRA e CHITARRA, 2005).

Mediante ao exposto, este trabalho teve como objetivo avaliar as características físicas e físico-químicas da água de coqueiro anão verde provenientes de diferentes regiões do Estado do Rio grande do Norte.

\section{Material e Métodos}

Foram selecionados frutos de coqueiro anão verde, colhidos de dois pomares situados em diferentes ambientes do Estado do Rio Grande do Norte. O primeiro ambiente se encontra localizado no Município de Assu-RN. A região desse pomar possui as coordenadas geográficas de $5^{\circ} 11^{\prime}$ de latitude sul e $37^{\circ}$ e $20^{\prime}$ de longitude oeste, com altitude media de $18 \mathrm{~m}$. O clima do local e do tipo BSwh', com base na classificação de Köppen e a média anual de precipitação é da ordem de $678 \mathrm{~mm}$. O segundo ambiente de coleta foi à região litorânea de Natal-RN, que apresenta latitude de $07^{\circ} 47^{\prime} 42^{\prime \prime}$ e longitude de $35^{\circ} 12^{\prime} 34^{\prime \prime}$, com clima tropical úmido e temperatura media de $28{ }^{\circ} \mathrm{C}$. Em cada um dos ambientes coletaram-se frutos de plantas escolhidas aleatoriamente no ponto de colheita comercial.

Os frutos foram colhidos pela manhã e colocados em sacos plásticos, sendo estes, posteriormente transportados, para o Laboratório de Fisiologia e Tecnologia Pós-Colheita da Universidade Federal Rural do Semi-Árido, do município de Mossoró-RN, no mês de novembro de 2008. Após a chegada, esses foram submetidos e avaliados quanto às seguintes características físicas: massa total do fruto (MT), que foi obtido utilizando-se balança semi-analítica e os resultados expressos em g; diâmetro longitudinal (DL), transversal (DT) e relação DL/DT, determinados com auxílio de paquímetro manual e todos os resultados expressos em centímetros.

Posteriormente, as avaliações físicas, procedeu-se a abertura dos frutos com o auxílio de um perfurador/extrator manual para a retirada do endosperma líquido e posterior medição do volume de água (VA) em proveta graduada, sendo estes resultados expressos em $\mathrm{mL}$. Também foi avaliada a relação volume de água e massa total do fruto (VA/MT) através do quociente entre as duas variáveis, expresso em $\mathrm{mL} \mathrm{kg}^{-1}$. 
Quanto às características físico-químicas, foram determinados os sólidos solúveis (SS), utilizando-se refratômetro digital e os resultados expressos em ${ }^{\circ} \mathrm{Brix}$; $\mathrm{pH}$, utilizando-se potenciômetro de acordo com a metodologia da Association of Official Analytical Chemists (2002); acidez titulável (AT), com resultados expressos em \% de ácido málico segundo Instituto Adolfo Lutz (1985) e relação SS/AT, obtida por meio do quociente entre SS e AT.

Adotou-se o delineamento inteiramente casualizado, em esquema fatorial $2 \times 3$, sendo o primeiro fator representado por dois ambientes de coleta e o segundo constituído por três plantas de cada pomar, com quatro repetições. A análise de variância das características avaliadas foi feita através do programa operacional software Sisvar, sendo a interação entre os fatores determinadas por meio do teste $\mathrm{F}$ a $5 \%$ de probabilidade.

\section{Resultados e Discussão}

Em relação ao diâmetro transversal dos frutos, não foi observada interação estatística significativa entre os ambientes de coleta e as plantas avaliadas (Tabela 1). A planta 1 foi a que apresentou o maior valor de diâmetro transversal (media de 15,45 cm) dentre todas as plantas estudadas. Os valores encontrados estão na mesma faixa dos observados por Maciel (2008).

Tabela 1- Diâmetro Transversal (DT), Diâmetro Longitudinal (DL), relação (DL/DT) de frutos de coqueiro anão verde cultivados em ambientes distintos do Estado Rio Grande do Norte, Mossoró-RN, UFERSA, 2009.

\begin{tabular}{cccc}
\hline $\begin{array}{c}\text { Fator / } \\
\text { Nivel }\end{array}$ & $\begin{array}{c}\text { DT } \\
(\mathbf{c m})\end{array}$ & $\begin{array}{c}\text { DL } \\
(\mathbf{c m})\end{array}$ & DL/DT \\
\hline Amb. 1 & $15,41 \mathrm{a}$ & $19,84 \mathrm{a}$ & $1,28 \mathrm{a}$ \\
Amb. 2 & $15,04 \mathrm{a}$ & $19,62 \mathrm{a}$ & $1,30 \mathrm{a}$ \\
\hline \multicolumn{5}{c}{} & Plantas & $1,28 \mathrm{a}$ \\
2 & $15,45 \mathrm{a}$ & $19,72 \mathrm{a}$ & $1,30 \mathrm{a}$ \\
3 & $15,42 \mathrm{a}$ & $20,03 \mathrm{a}$ & $1,32 \mathrm{a}$ \\
C.V. & $14,80 \mathrm{a}$ & $19,42 \mathrm{a}$ & 6,67 \\
\hline
\end{tabular}

Médias seguidas de mesma letra, entre níveis de cada fator, não diferem entre si ( $p>0,05)$ pelo teste de Tukey.

Com relação ao diâmetro longitudinal dos frutos, não foi observada interação significativa entre os ambientes de coleta e as plantas avaliadas (Tabela 1). Para este parâmetro a planta 1 apresentou o maior valor de 20,03 cm, não diferindo estatisticamente das demais plantas. Os valores médios encontrados variaram de 19,42 a 20,03 cm, estando na faixa encontrados por Maciel (2008) e Araújo (2003) quando trabalhou com a mesma espécie. Foi observado que todas as plantas apresentaram o diâmetro longitudinal de frutos sempre maior que o diâmetro transversal, fato esse também observado por Silva (2006).

Para a relação DL/DT de frutos de coqueiro anão verde, não foi observada interação significativa entre os ambientes de coleta e as plantas avaliadas (Tabela 1). 
A planta 3 apresentou valor médio estatisticamente superior às demais plantas quanto à relação diâmetro longitudinal e transversal, sendo, portanto, considerada como a que possui o fruto mais arredondado. Essa relação é indicadora do formato do fruto, que é mais arredondado à medida que este quociente aproxima-se de 1,0. As indústrias dão maior preferência aos frutos arredondados, por facilitarem as operações de limpeza e processamento (CHITARRA e CHITARRA, 2005).

Os dados médios de comprimento e largura obtidos por Aroucha (2000), quando convertidos para a relação DL/DT, aos 8 e 10 meses de idade do coqueiro anão verde $(1,24$ e 1,28$)$ estão próximos aos obtidos neste estudo. Shimizu (2006), quanto trabalhou com esta mesma espécie observou resultados semelhantes.

Com relação à massa fresca dos frutos, foi observado efeito estatístico significativo da interação entre os ambientes de coleta e as plantas do referido estudo (Tabela 2). A planta 1 no ambiente 2 se caracterizou com o maior valor de massa $2.396 \mathrm{~kg}$. No entanto, a planta 2 do mesmo ambiente apresentou o menor valor de massa fresca $1.867 \mathrm{~kg}$.

Tabela 2- Massa fresca (MF), Volume de Água (VA), relação (MF/VA) de frutos de coco anão verde cultivados em ambientes distintos do Rio Grande do Norte, Mossoró-RN, UFERSA, 2009

\begin{tabular}{|c|c|c|c|c|c|c|}
\hline \multirow[t]{2}{*}{ Planta } & \multicolumn{2}{|c|}{ MF (Kg) } & \multicolumn{2}{|c|}{ VA (mL) } & \multicolumn{2}{|c|}{ MF/VA (mL kg $\left.{ }^{-1}\right)$} \\
\hline & Amb. 1 & Amb. 2 & Amb. 1 & Amb. 2 & Amb. 1 & Amb. 2 \\
\hline 1 & $2.118,1 \mathrm{aA}$ & $2.396,2 \mathrm{aA}$ & $531,2 \mathrm{aA}$ & $347,5 \mathrm{bB}$ & $3,99 \mathrm{bB}$ & $6,89 \mathrm{aA}$ \\
\hline 2 & $2.276,0 \mathrm{aA}$ & $1.867,5 \mathrm{bB}$ & $450,0 \mathrm{aB}$ & $427,0 \mathrm{aA}$ & $5,07 \mathrm{aA}$ & $4,37 \mathrm{bB}$ \\
\hline 3 & $2.061,6 \mathrm{aA}$ & $1.920,0 \mathrm{aB}$ & $411,2 \mathrm{aB}$ & $401,0 \mathrm{aAB}$ & $5,02 \mathrm{aA}$ & $4,81 \mathrm{aB}$ \\
\hline C.V & & & & & & \\
\hline
\end{tabular}

Letras iguais, maiúsculas nas colunas e minúsculas nas linhas, para cada planta de coco, não diferem entre si ao nível de $5 \%$ de probabilidade pelo teste de Tukey.

Araújo (2001), estudando a cultivar anão verde do jequi, observou que as massas dos frutos aumentaram até os 210 dias de desenvolvimento, ocorrendo a partir daí um decréscimo, independentemente da cultivar. Essas pequenas diferenças entre os resultados aqui apresentados e os de Silva (2006) e Araújo (2001) podem ser devidas ao fato de uma mesma cultivar poder ter comportamento diferente conforme a estação de cultivo, pois fatores como irrigação, adubação e fitossanidade influenciam no desenvolvimento dos frutos (SREBERNICH, 1998).

A diminuição no peso dos frutos está associada à perda de água do mesocarpo no final da maturação (CASTRO e MAIA, 1985); enquanto, a redução no volume da água ou endosperma líquido é resultante dos processos bioquímicos que incorporam o endosperma líquido em endosperma sólido (MEDINA, 1980; ARAGÃO et al., 2001). 
O volume de água do fruto foi dependente da interação entre as plantas e os ambientes de coleta (Tabela 2). A planta 1 do ambiente 1 apresentou o maior volume de água se sobressaindo em relação as demais, com um valor médio de $531 \mathrm{~mL}$. No entanto, a planta 3 apresentou os menores valores de volume de água em ambos os ambientes de coleta, com valores médios de 411 e $401 \mathrm{~mL}$, respectivamente.

No que se refere à produção de frutos para consumo in natura, o volume de água é uma das características que é mais importante aos produtores e consumidores, pois o que se leva em conta, além da qualidade, é a quantidade de água produzida pelas diferentes cultivares.

Souza et al. (2002), recomenda que quando o objetivo for também o consumo de água de coco verde, deve-se optar por efetuar a colheita quando os frutos atingirem o sétimo mês de desenvolvimento em função das melhores características organolépticas apresentadas pela água. Por outro lado, Aragão et al. (2001) recomendam que a colheita dessas mesmas cultivares, seja feita aos 180 dias de desenvolvimento após a polinização, em virtude de apresentarem maiores massas do fruto e volume de água acumulado.

O volume de água no fruto do coco, tanto é dependente da cultivar, quanto do estádio de maturação do fruto (JACKSON et al., 2004). Segundo Aroucha (2000) mudanças no volume de água das cultivares Anão Verde do Jequi e Anão Vermelho foram observadas conforme o estádio de maturação. Os resultados dos volumes de água do presente trabalho estão acima dos apresentados por Jaylekshmy et al. (1986) e Tavares et al. (1998).

Foi observada interação significativa para a relação massa do fruto e volume de água (Tabela 2) entre os ambientes de coleta e plantas analisadas. A planta $1 \mathrm{em}$ ambos os ambientes apresentou o maior $(6,89)$ e menor $(3,99)$ valor de relação massa do fruto e volume de água.

O volume de água de certa quantidade de frutos pode ser estimado a partir dessa relação. Daí, sua utilidade. Sua importância já foi relatada por Srebernich (1998); Assis et al. (2000) e por Araújo (2003). Por esses estudos, concluiu-se que a relação entre o volume de água e a massa do fruto pode variar conforme cultivar, idade do fruto e a safra, além do número de frutos por cacho e número de frutos por planta.

De acordo com a Tabela 3, houve interação estatística significativa entre os ambientes de coleta e as plantas de coqueiro anão verde analisadas com relação à acidez da água de coco. Pode-se verificar que a planta 3 proveniente do ambiente 2 apresentou o maior valor $(0,060 \%)$ de acidez, enquanto que no ambiente 1 , pode-se observar um maior valor $(0,025 \%)$ de acidez para a planta 1 . Em geral, não foram observadas grandes diferenças na acidez da água entre as plantas estudadas. 
Tabela 3. Acidez titulável (AT), Sólidos soluveis (SS), Relação (SS/AT) e pH de frutos de coco anão verde cultivados em ambientes distintos do Rio Grande do Norte, Mossoró-RN, UFERSA, 2009.

\begin{tabular}{|c|c|c|c|c|c|c|c|c|}
\hline \multirow[t]{2}{*}{ Planta } & \multicolumn{2}{|c|}{$\begin{array}{c}\text { AT } \\
\text { (\% ác. Málico) }\end{array}$} & \multicolumn{2}{|c|}{$\begin{array}{c}\text { SS } \\
\left({ }^{\circ} \text { Brix }\right)\end{array}$} & \multicolumn{2}{|c|}{ SS/AT } & \multicolumn{2}{|c|}{ pH } \\
\hline & Amb. 1 & Amb. 2 & Amb. 1 & Amb. 2 & Amb. 1 & Amb. 2 & Amb. 1 & Amb. 2 \\
\hline 1 & $0,025 \mathrm{aA}$ & $0,025 \mathrm{aA}$ & $5,42 \mathrm{bB}$ & $7,10 \mathrm{aA}$ & $244,6 \mathrm{bB}$ & $372,5 \mathrm{aA}$ & $4,75 \mathrm{bB}$ & $5,05 \mathrm{aA}$ \\
\hline 2 & $0,020 \mathrm{aA}$ & $0,020 \mathrm{aB}$ & $6,07 \mathrm{bA}$ & $6,70 \mathrm{aA}$ & $365,7 \mathrm{aA}$ & $403,4 \mathrm{aA}$ & $4,97 \mathrm{aA}$ & $5,03 \mathrm{aA}$ \\
\hline 3 & $0,020 \mathrm{bA}$ & $0,060 \mathrm{aA}$ & $6,30 \mathrm{aA}$ & $5,30 \mathrm{bB}$ & $379,3 \mathrm{aA}$ & $392,56 \mathrm{bB}$ & $4,94 \mathrm{aA}$ & $4,59 \mathrm{bB}$ \\
\hline C.V & \multicolumn{2}{|c|}{20,59} & \multicolumn{2}{|c|}{3,75} & \multicolumn{2}{|c|}{17,92} & \multicolumn{2}{|c|}{1,22} \\
\hline
\end{tabular}

Letras iguais, maiúsculas nas colunas e minúsculas nas linhas, para cada planta de coco, não diferem entre si ao nível de $5 \%$ de probabilidade pelo teste de Tukey.

Os resultados aqui observados, em geral, foram semelhantes aos encontrados por Aragão et al. (2002) e Araujo (2003).

O ácido málico é o acido orgânico predominante na água de coco, o qual se encontra em proporção superior a 90\% dos ácidos graxos presentes. Por isso, este é o ácido que melhor expressa a acidez da água de coco (SREBERNICH, 1998). A legislação brasileira para acidez de água de coco estabelecida por Brasil (2002) tem limites máximos e mínimos de 0,03\% e de 0,18\%.

Pelos resultados de acidez encontrados nesse trabalho pode-se afirmar que esta característica não é boa indicadora para auxiliar na determinação do ponto de colheita do coco, dada as baixas proporções de ácidos presentes na água. Santos Filha et al. (2005) relatam que a acidez dessa cultivar não foi diferente quando os frutos estavam com 180 e 210 dias de idade. $\mathrm{O}$ valor de acidez encontrado no presente trabalho esta na faixa dos encontrados por Jayalekshmy et al. (1988).

De acordo como modelo estatístico empregado, foi observada interação significativa entre os ambientes de coleta e as plantas analisadas com relação ao $\mathrm{pH}$ da água de coco (Tabela 3). Verificou-se que a planta 1 do ambiente 2 obteve o maior valor de $\mathrm{pH}$, seguido pela planta 2 do mesmo ambiente, com valores de 5,05 e 5,04, respectivamente. Os valores de $\mathrm{pH}$ do presente estudo estão próximos aos detectados em água de coco destinados ao consumo por Campos et al. (1996).

Maciel (2008) e Aroucha (2000) quando trabalharam com esta mesma espécie observaram valores semelhantes aos encontrados no trabalho. Silva (2006) estudando esta espécie verificou que entre 180 e 195 dias de desenvolvimento o $\mathrm{pH}$ variou na faixa de 5,27 a 5,55, valores estes muito próximo do encontrado por Araújo (2003) ou seja, 5,63 aos 182 dias de desenvolvimento, que é a faixa, onde normalmente, o sabor doce e a adstringência para a água de coco são desejáveis.

De acordo Kays (1991), alguns frutos se caracterizam pelo decréscimo no teor de ácidos durante o amadurecimento, como conseqüência principal da atividade metabólica do fruto, o que ocasiona a elevação no $\mathrm{pH}$.

Para essa variedade de coco, é importante mostrar que todos os valores de pH para as diferentes plantas apresentaram-se dentro dos limites estabelecidos por Brasil (2002), o que permite um valor mínimo de $\mathrm{pH}$ de 4,30. 
Foi observada, neste trabalho interação estatística significativa entre os ambientes de coleta dos frutos e plantas analisadas (Tabela 3). A planta que obteve o maior valor dessa relação foi a 2 proveniente do ambiente 2, com um valor médio de 403,4, enquanto que a 1 do mesmo ambiente foi a que se caracterizou com um menor valor de 372,50 desta relação.

Isepon et al. (2002), estudando este atributo com a mesma espécie do referido estudo, encontrou valores numa faixa de 49 a 219 , a partir do sexto até o décimo primeiro mês de desenvolvimento do fruto.

Os altos valores obtidos para esta relação são devidos à baixa acidez do albúmen liquido, conforme norma pra fixação de identidade e qualidade da água de coco do Ministério da Agricultura, que determina o mínimo de 0,03 e o máximo de 0,18 g de ácido málico.

A relação SS/AT é muito importante, pois é um excelente indicador de doçura e está diretamente relacionada com o aroma e o sabor da água de coco (CHITARRA e CHITARRA, 2005).

O conteúdo dos sólidos solúveis na água foi significativo para a interação ambientes de coleta e plantas analisadas (Tabela 3). Pode-se verificar que houve uma variação de 5,30 a 7,10 entre as plantas para valores de sólidos solúveis, tendo a planta 1 do ambiente 2 o maior resultado para esta variável.

Considerando-se a relação entre os sólidos solúveis totais e o teor de açúcar total e, consequentemente, a manifestação do sabor e a doçura da água, uma vez que, em grande percentagem é representada pelos açúcares, existindo por tanto, uma forte correlação dessa característica com a qualidade final da água entre as diferentes cultivares. Diante disso, Jackson et al. (2004) recomendam que essa característica pode ser utilizada como indicador da doçura na água de coco.

Não existe definido ainda, no mercado consumidor, um limite mínimo de sólidos solúveis para a aceitação da água de coco e nem mesmo para essas cultivares. No entanto, alguns autores apontam como entre 5,0 e 6,0 \% (JACKSON et al., 2004); 6,0 e 7,0 \% (ARAÚJO, 2003); 5,2 e 9,2 $\%$ (ARAGÃO et al., 2002); 7,37 e 7,58 \% (ISEPON et al., 2002) e 5,84 e 6,71 \% (AROUCHA, 2000) como sendo ideais por ocasião da colheita para a grande maioria das cultivares de coqueiro anão, estando os valores deste trabalho na mesma faixa dos referidos autores citados.

\section{Conclusão}

De acordo com as condições em que este experimento foi realizado, conclui-se que:

Com relação ao diâmetro transversal e longitudinal dos frutos, o ambiente de Assu-RN apresentou os maiores valores, com médias de 15,41 e 19,84 cm. Para a relação DL//DT, o 
ambiente de Natal-RN apresentou valor médio de 1,30. Em relação à massa fresca e volume de água, o ambiente de Assu-RN, obteve maior valor médio $(2.151,90 \mathrm{~kg}$ e 464,13 mL, respectivamente). Para a relação VA/MF, Natal-RN, apresentou maior valor médio $\left(5,35 \mathrm{~mL} \mathrm{~kg}^{-1}\right)$.

De acordo com os resultados obtidos, foi possível observar que ocorreram diferenças, em ambos os ambientes de cultivo, para todas as características físico-químicas avaliadas. Entretanto, os valores médios de Natal-RN, foram superiores em todos os atributos avaliados, com acidez de 0,03\% de ácido málico, sólidos solúveis 6,36 ${ }^{\circ}$ Brix, SS/AT 389,48 e pH 4,80. Os resultados deste experimento mostraram que as plantas de coqueiro anão verde, podem ser exploradas comercialmente, devido às qualidades físicas e físico-químicas que apresentaram.

\begin{abstract}
In recent years, farmers in the Northeast of Brazil has been cultivating the coconut tree, seeking commercialization of water the green fruit. In literature there are few reports on production and quality of coconut in the region, because they are few producers who were motivated to produce fruit. In order to investigate the quality of coconut water and fresh fruit was produced the work. The fruits was harvested of the Rio Grande do Norte state. After the harvest times, was performed for in the Postharvest Laboratory of UFERSA, in Mossoro, RN. The evaluated fruit physical: transversal diameter $(\mathrm{cm})$, longitudinal diameter $(\mathrm{cm}), D L / D T$, fresh mass $(\mathrm{kg})$, water volume $(\mathrm{mL}), \mathrm{MF} / \mathrm{VA}$ $\left(\mathrm{mL} . \mathrm{kg}^{-1}\right)$, and the evaluated physical-chemical of coconut water: soluble solids ( ${ }^{\circ}$ Brix $), \mathrm{pH}$, titratable acidity (\%) and SS/AT. The experiment was driven in design completely, in factorial array $2 \times 3$, with four repetitions. With regard to transversal and longitudinal diameter of fruits, the environments conditions of Assu-RN, presented the biggest values, with averages de 115,41 and $19,84 \mathrm{~cm}$, respectively. In relation the fresh mass and water volume, the environments of Assu-RN, presented higher average value $(2.151,90 \mathrm{~kg}$ and $464,13 \mathrm{~mL}$, respectively). For ratio VA/MF, Natal-RN, presented higher average value $\left(5,35 \mathrm{~mL} \mathrm{Kg}^{-1}\right)$. It was observed that changes occurred, for all the physical-chemical characteristics evaluated. However, the average values of Natal-RN, was superiors in all the evaluated attributes, with acidity of 0,003\%, soluble solids 6,36 ${ }^{\circ}$ Brix, SS/AT 389,48 and $\mathrm{pH} 4,80$.
\end{abstract}

Key words: Cocus nucifera L., characterization, quality, water volume.

\title{
Referências
}

ALEIXO, P. C.; NÓBREGA, J. A. Determinação direta de selênio em água de coco e em leite de coco utilizando espectrometria de absorção atômica com atomização eletrotérmica em forno de grafite. Química Nova, v. 23, n. 3, p. 310-312, 2000. http://dx.doi.org/10.1590/S0100-40422000000300005

ARAGAO, W. M.; ISBERNER, I. V.; CRUZ, E. M. de O. Água de coco. Aracaju: Embrapa Tabuleiros Costeiros, 2001. (Embrapa Tabuleiros Costeiros, 24).

ARAGÃO, W. M. Coco pós-colheita. Frutas do Brasil. [Aracajú]: EMBRAPA/CPATC, 2002. 75p.

ARAÚJO, M. V. Ponto de colheita e armazenamento refrigerado de coco Anão Verde (Cocus nucífera L.) sob atmosfera modificada. Mossoró-RN, 62p. (Dissertação de Mestrado) - ESAM. 2003.

ARAÚJO, M. V. Conservação pós-colheita de coco Anão Verde (Cocus nucífera L.) sob atmosfera modificada. Congresso Brasileiro de Fruticultura Belém-PA, CD-ROM. 2001. 
AROUCHA, E. M. M. Avaliação das principais características físicas e físico-químicas do endosperma líquido e sólido das cultivares de coco anão (cocos nucífera $L$ ) verde e vermelho em diferentes estádios de maturação. 2000. Tese (Mestrado)-Centro de Ciências e Tecnologias Agropecuárias, Universidade Estadual do Norte Fluminense, Campos de Goytacazes, 2000.

AROUCHA, E. M. M; VIANNI, R. Determinação de ácido ascórbico na água-de-coco (Cocus nucifera L.) por cromatografia líquida e pelo método titulométrico. Revista Ceres, Viçosa/MG, v. 49, n. 283, p.245-251, 2002.

ASSIS, J. S.; RESENDE, M. J.; SILVA, O. F.; SANTOS, R. C.; NUNES, F. Técnicas para colheita e pós-colheita do coco verde. Petrolina: Embrapa Semi-Árido, 2000. 6p. (Embrapa Semi-Árido. Comunicado Técnico, 95).

ASSOCIATION OF OFFICIAL ANALYTICAL CHEMISTS. Official methods of analysis of AOAC International. 17th ed. New York, 2002.

BRASIL. Ministério da Agricultura, Pecuária e Abastecimento. Anuário Brasileiro de Fruticultura. Santa Cruz do Sul. Ed. Gazeta Santa Cruz, 2004.

BRASIL. Ministério do Meio Ambiente, dos Recursos Hídricos e da Amazônia Legal. Coco verde. Disponível em: www.integracao.gov.br/pdf/frutiseries/frutiseries sp 03.pdf. Acesso em: 13 mar. 2002.

CAMPOS, C. F.; SOUZA, P. E. A.; COELHO, J. V.; GLÓRIA, M. B. A. Chemical composition, enzyme activity and effect of enzyme inactivation on flavor quality of green coconut water. Journal Food Processing Preservation, New York, v. 20, n. 6, p. 487-500, 1996. http://dx.doi.org/10.1111/j.1745-4549.1996.tb00761.x

CAStro, F. A.; MAIA, G. A. Coco: Leite e Coco Ralado. Fortaleza: Fundação Núcleo de Tecnologia Industrial, 1985. 47p.

CHITARRA, M. I. F.; CHITARRA, A. B. Pós-colheita de frutos e hortaliças: Fisiologia e manuseio. 2 ed. Lavras: Editora UFLA, 2005.

CUENCA, M. A. G.; RESENDE, J. M.; SAGGIN JÚNIOR, O. J.; REIS, C. S. Mercado brasileiro do côco: situação atual e perspectivas. In: ARAGÃO, W. M. Coco: pós-colheita. Brasília, DF: Embrapa Informação Tecnológica, 2002. p. 18.

EMBRAPA. Centro de Pesquisa de Tecnologia de Alimentos. (Guaratiba, RJ). Processamento de água de coco verde. Guaratiba: EMBRAPA/CTAA: 1998. 10p. (Comunicado Técnico)

IBGE. Levantamento sistemático da produção agrícola. Rio de Janeiro: Sistema IBGE de recuperação automática. SIDR,disponível em: <http:// www.ibge.gov.br>. Acesso em: agosto de 2007.

INSTITUTO ADOLFO LUTZ. Normas Analíticas do Instituto Adolfo Lutz. Métodos químicos e físicos para análise de alimentos. 3. ed. São Paulo, v. 1, 1985.

ISEPON, J. S. et al. (sic) Monitoramento da qualidade de frutos de coqueiro Anão (Cocus nucifera L.) em diferentes estádios de maturação. In: CONGRESSO BRASILEIRO DE FRUTICULTURA. 2002, Belém. Anais...Pará: SBF, 2002. CR-ROM.

JACKSON, J. J.; GORDON, A.; WIZZARD, G.; MCCOOK, K.; ROLLE, R. Changes in chemical composition of ccoconut (Cocus nucifera L.) water during maturation of the fruit. Journal of the Science of Food and Agriculture. v. 84, n. 9, p. 1049-1052, 2004. http://dx.doi.org/10.1002/jsfa.1783

JAYALEKSHMY, A. et al. (sic) Changes in the chemical composition of coconut water during maturation. Oléaneux, Paris, v. 43, n. 11, p. 409-412, 1988.

KAYS, J. S. Postharvest physiology of perishables plant products. New York: AVI, 1991. 543p.

MACIEL, V.T. Caracterização fisica, fisico-química e enzimática de frutos de seis cultivares de coqueiro anão em diferentes estadios de desenvolvimento. Dissertação de Mestrado, UFC. p. 102. 2008.

MEDINA, J. C. Processamento: cultura-variedades; produtos, características e utilização - bebidas destiladas água de coco - Da Cultura ao Processamento e Comercialização. São Paulo: [s.n], 1980. 252p. (Série Frutas Tropicais no 5). 
OliveirA, M. E. B.; BASTOS, M. S. R.; FEITOSA, T.; BRAnCO, M. A. A. C.; SILVA, M. G. G. Avaliação de parâmetros de qualidade físico-químicos de polpas congeladas de acerola, cajá e caju. Ciência e Tecnologia de Alimentos, Campinas, v. 19, n. 3, set./dez., p. 326-332, 1999. http://dx.doi.org/10.1590/S0101-20611999000300006

PASSOS, E.E.M. Morfologia do Coqueiro. In: FERREIRA, J. M. S.; WARWICK, D. R. N.; SIQUEIRA, L. A. (Ed.). A cultura do coqueiro no Brasil. 2. ed. Brasília: Embrapa - Serviço de Produção de Informação, 1998. p. 57-64.

SANTOS FILHA, M.E.C.S. et al. (sic) Qualidade da água de fruto de seis cultivares de coqueiro Anão para consumo in natura e/ou industrializado. In: SIMPÓSIO BRASILEIRO DE PÓS-COLHEITA DE FRUTOS TROPICAIS. I, 2005, João Pessoa, Anais... João Pessoa, PB: (SBPCFT), 2005, 5 p. CD ROM.

SHIMIZU, M. K.; CONEGLIAN, R. C. C. ;BUSQUET, R. N. B.; VASCONCELlOS, M. A. S.; SHIMIZU, E. S. C. Influência da idade na variação dos constituintes de frutos de coqueiro anão-verde (Cocus nucifera $\mathrm{L}$.) da região da baixada de sepetiba/RJ. Agronomia, v. 40, n. 1-2, p. 40- 45, 2006.

SILVA, F. V. G. Bebidas à base de água de coco e suco de maracujá: processamento e estabilidade. Fortaleza, 2006. 76 p. Dissertação (Mestrado em Tecnologia de Alimentos), Universidade Federal do Ceará.

SOUZA, V. A. B.; NOGUEIRA, C. C. P.; SOUZA. H. V.; CARNEIRO, J.; VAL, A. D. B. Avaliação de cultivares de coqueiro Anão na micro região do Baixo Parnaíba Piauiense: características de desenvolvimento vegetativo. In: CONGRESSO BRASILEIRO DE FRUTICULTURA, 17., 2002, Belém. Anais.... Belém: CBF, 2002. (CD - ROM).

SREBERNICH, S.M. Caracterização física e química da água de fruto de coco (Cocus nucifera $\mathbf{L}$.), variedades gigante e híbrido PB-121, visando o desenvolvimento de uma bebida com características próximas às da água de coco. Campinas, 1998. 189 p. Tese (Doutorado em Tecnologia de Alimentos), Universidade Estadual de Campinas.

TAVARES, M. et al. (sic) Estudo da composição química da água de coco Anão Verde em diferentes estádios de maturação. In: CONGRESSO BRASILEIRO DE CIÊNCIAS ETECNOLOGIA DE ALIMENTOS, 16. Rio de Janeiro. Anais... Rio de Janeiro: SBCTA, 1998. v. 2, p.1262-1265. 1998.

Submetido em 22 mai 2012, Aceito para publicação em 26 dez. 2012. 